\title{
PerCursos
}

\section{O coração vulnerável: a masculinidade negra do sujeito periférico brasileiro cantada pelos Racionais MC's, em Jesus Chorou}

\begin{abstract}
Resumo
Expressões artísticas como o rap são capazes de ecoar as mais distintas vozes que se interseccionam na sociedade e permitem trazer à arena discursiva inúmeras questões sociais candentes. A canção Jesus chorou, do grupo Racionais MC's foi empregada neste estudo visando a uma análise social crítica, na medida em que narra complexos contextos do cotidiano de brasileiros vulnerabilizados e historicamente marginalizados e/ou compreendidos de maneira demasiadamente reducionista sob um olhar "estrangeiro". A partir da divisão da canção em cinco partes, adotou-se uma contextualização endoperspectivada dos ambientes trazidos nas metáforas dos versos compostos por Mano Brown. A análise salienta a figura do homem negro periférico em termos do seu sofrimento psíquico derivado de uma estruturação socioeconômica, cultural e histórica excludente, além da questão da masculinidade e emocionalidade negra na sua construção identitária e no seu desenvolvimento social e familiar. Problematizações acerca desses lugares ocupados pelo homem negro periférico são endereçadas ao longo do estudo, reforçando a narrativa poética do rap como recurso potente de visibilidade, resistência e autoria coletiva.
\end{abstract}

Palavras-chave: Racismo. Masculinidade. Periferias. Racionais MC's. Rap (Música).
Ronan da Silva Parreira Gaia

Mestrando em Ciências pelo

Programa de Pós-Graduação em

Enfermagem Psiquiátrica da

EERP/USP.

Brasil

ronangaia@yahoo.com.br

\section{Alice da Silva Vitória}

Licenciada em Ciências Sociais pela

Universidade Federal de Viçosa - UFV.

Especialista em Ensino de História da

África pelo Colégio Pedro II.

Brasil

lili-asv@hotmail.com

\section{Cristina Aparecida Silva}

Licenciada em Pedagogia pela

Univ. de Ribeirão Preto -

UNAERP. Especialista em Ed.

Especial e Inclusiva pela

Faculdade de Educação São Luís.

Brasil

cris_asrp@icloud.com

\section{Fabio Scorsolini-Comin}

Doutor em Psicologia pela

Universidade de São Paulo - USP.

Profesor da Escola de

Enfermagem de Ribeirão Preto

da Univ. de São Paulo -USP.

Brasil

fabio.scorsolini@usp.br

\section{Para citar este artigo:}

GAIA, Ronan da Silva Parreira; VITÓRIA, Alice da Silva; SILVA, Cristina Aparecida; SCORSOLINI-COMIN, Fabio. O coração vulnerável: a masculinidade negra do sujeito periférico brasileiro cantada pelos Racionais MC's em Jesus Chorou. PerCursos, Florianópolis, v. 21, n.46, p. 162 -189, maio/ago. 2020. 


\title{
The vulnerable heart: the black masculinity of the brazilian peripheral singed by Racionais MC's in Jesus Chorou
}

\begin{abstract}
Artistic expressions like rap can echo the most distinct voices that intersect in society and bring numerous burning social issues to the discursive arena. The song "Jesus cried" (Jesus chorou), by the group Racionais MC's was used in this study aiming at critical social analysis, as it narrates complex daily contexts of vulnerable and historically marginalized Brazilian people and/or understood in a way that is too reductionist under an "outsider" look. Based on the division of the song into five parts, an endoperspective contextualization of the environments adopted in the metaphors of the verses composed by Mano Brown was adopted. The analysis highlights the figure of the peripheral black man in terms of his psychological suffering derived from an exclusive socioeconomic, cultural, and historical structure, besides black masculinity and emotionality in his identity construction and social and family development. Problematizations about these places occupied by peripheral black men are addressed throughout the study, reinforcing rap's poetic narrative as a powerful resource of visibility, resistance, and collective authorship.
\end{abstract}

Keywords: Racism. Masculinity. Periphery. Racionais MC's. Rap (Music). 


\section{Introdução}

Em fins do século passado, se desenvolvia a arte de um grupo de rap da periferia da cidade de São Paulo, chamado Racionais MC's. Hoje, trata-se de um grupo famoso e reconhecido por dar voz às realidades esquecidas e marginalizadas pela sociedade brasileira. Entre as diversas músicas que se tornaram clássicos do rap nacional, como Diário de um Detento, Negro Drama, Fórmula Mágica da Paz, entre outras, a música Jesus Chorou chama atenção por ser uma longa narrativa que aborda diversas situações, de forma que permite elencar questões raciais e sociais, tais como a importância da religiosidade, da ancestralidade e/ou da fé e a existência da tristeza e da angústia no contexto das desigualdades. A canção também possibilita uma pertinente análise social, na medida em que desconstrói um conceito de masculinidade machista e abusivo, fortemente presente nas periferias brasileiras, de que o homem não pode chorar: a música contraria essa norma social, justificando que é permitido, sim, o choro daqueles nascidos com falo, posto que até Jesus Cristo, com toda a sua santidade, ele, o filho do deus cristão, chorou'1. A canção foi lançada em 2002 no álbum Nada como um Dia após outro Dia ${ }^{2}$, quinto disco do grupo, e foi escrita pelo cantor Mano Brown.

Anteriores a Nada como um Dia após outro Dia, o grupo Racionais MC's conta com o EP Holocausto Urbano 3 e com os álbuns Escolha o Seu Caminho ${ }^{4}$, Raio X do Brasil5 e Sobrevivendo no Inferno ${ }^{6}$. Este último foi o responsável por fazer com que o grupo expandisse de forma significativa seu sucesso devido às letras didáticas e à linguagem acessível à população que ali se viu representada. O diferencial de Sobrevivendo no Inferno (1997) foi sua organização, semelhante a um culto religioso, sob a ótica de um evangelho marginal, alcançando, assim, cerca de 1,5 milhão de vendas e atingindo brasileiros de diferentes classes sociais (OLIVEIRA, A., 2018).

\footnotetext{
${ }^{1}$ Conforme narrado em João 11:35 (BÍBLIA, 2008, p. 1636), Lucas 19:41 (BÍBLIA, 2008, 1595) e Hebreus 5:7 (BÍBLIA, 2008, p. 1852).

2 São Paulo: Casa Nostra/Zambia, 2002. 2 CDs.

3 São Paulo: RDS Fonográfica/Zimbabwe Records, 1990. CD.

${ }^{4}$ São Paulo: Zimbabwe Records, 1992. CD.

${ }^{5}$ São Paulo: Zimbabwe Records, 1993. CD.

${ }^{6}$ São Paulo: Casa Nostra/Zambia, 1997. 2 CDs.
} 
As vivências periféricas no Brasil, até então, eram pouco ou mal abordadas na música. As pesquisas acadêmicas acerca das realidades periféricas ainda hoje merecem as denúncias (GOULART; CALVET, 2017) que problematizam suas reais intenções. Com recorrentes pesquisas e percepções negativas incutidas no senso comum desde o início de sua existência e no papel do Outro fanoniano, as favelas buscam expressar sua voz das mais diversas maneiras e falando a partir de si mesmas. Entende-se que não ser escutado leva o sujeito à inexistência, pois, "falar é existir absolutamente para o outro" (FANON, 2008, p. 33). Dessa maneira, ignorar essas vozes seria equivalente a sujeitá-las à inexistência social, o que configura o processo de marginalização de suas insistentes existências. Entretanto, a fala e a voz desses sujeitos são sinônimos da participação cidadã do sujeito periférico (ARAÚJO, 2013) e partem de uma população marginalizada e por muito tempo silenciada. Nesses termos, o grupo Racionais MC's atua de maneira

[...] decisiva para fazer do rap muito mais que uma simples representação da periferia. Sua radicalidade e seu senso de "missão" (afinal, "rap é compromisso", já dizia Sabotage) ajudaram a desenvolver um espaço discursivo em que os cidadãos periféricos puderam se apropriar de sua própria imagem, construindo para si uma voz que, no limite, mudaria a forma de enxergar e vivenciar a pobreza no Brasil. (OLIVEIRA, A., 2018, p. 23)

Face ao exposto, convém ressaltar que o histórico silenciamento das periferias não significa a sua inexistência ou a inexistência de sua voz. Talvez o diferencial das palavras entoadas pelo grupo paulistano aqui analisado seja justamente fazer essas vozes serem notadas para além das periferias, ampliando audiências e multiplicando as ressonâncias desse campo.

Com isso, pretende-se aqui abrir espaço para refletir sobre as contribuições do rap dos Racionais MC's enquanto forma de resistência e denúncia às desigualdades sociorraciais no Brasil, por meio de análise da poesia metaforizada de Jesus Chorou. Também interessa aqui examinar a emocionalidade do homem periférico, forte questão posta na música, inclusive, como indica o próprio título. Entende-se que a letra trata de inúmeras questões caras à sociedade e que demandam por pesquisas acadêmicas que 
ultrapassem as perspectivas preconceituosas que historicamente foram admitidas pelas academias brasileiras ao tratar de classes marginalizadas (DALCASTAGNÈ, 2008; FREYRE, 2005; GOULART; CALVET, 2017).

Além disso, outras canções do grupo, como a memorável Negro Drama e Diário de um Detento, já foram alvo de análises científicas (OLIVEIRA, E., 2018; RIBEIRO; FAUSTINO, 2017), assim como a própria narrativa poética do grupo (FERNANDES; HERSCHMANN; GUTIERREZ, 2016). Para a análise de Jesus Chorou, parte-se do que Sodré (2017) concebe como endoperspectiva, ou seja, com o pesquisador íntimo de seu campo de estudo. Desse modo, o primeiro autor deste estudo é um homem negro, oriundo de periferia e que, portanto, não recebe a proteção da cor da pele, comumente desfrutada por aqueles que são sujeitos brancos (HARRIS, 1993). Assim, ao passo que sente cotidianamente as dimensões do racismo estrutural que acompanha o Brasil desde a dominação portuguesa (ALMEIDA, 2018; CICONELLO, 2008), este possui legitimidade para estruturar uma análise endoperspectivada do tema.

Para empreender a análise, a canção foi dividida e organizada em cinco partes, de acordo com as mudanças situacionais observadas ao longo da análise da obra em tela. A divisão da música mantém sua forma textual original (RACIONAIS MC'S, 2002), porém de maneira adaptada com as partes do estudo e suas narrativas. Entendendo que parte do diálogo se organiza como narrativas entre o autor e seu alter-ego interlocutor, percebemos ser propícia a estruturação que identifica o começo da canção a partir da metaforização da lágrima e da tristeza, que logo dá espaço para uma segunda parte, em que o interlocutor relata a mágoa e a superação que podem ser encontradas nas dificuldades comuns a todos os moradores das periferias. A partir daí, costura-se de maneira mais robusta uma problematização acerca do racismo na sociedade brasileira, seguida da apresentação da rigidez dessa mesma estrutura racista corporificada no país. Logo mais, a ideia da possibilidade de um preto favelado ser um vencedor, nesse contexto inóspito, encerra a reflexão exposta pela canção escolhida para análise. 


\section{Primeira parte: a tristeza metaforizada em uma lágrima}

No primeiro momento, enfatiza-se a dor pelo processo fisiológico da lágrima. Aqui são expostos os sentimentos incutidos nos sujeitos periféricos pela realidade que vivenciam. É através da indagação (“o que é, o que é?”) que as reflexões da poesia começam a ser costuradas, conforme exposto a seguir:

O que é, o que é? / Clara e salgada / Cabe em um olho e pesa uma tonelada / Tem sabor de mar / Pode ser discreta / Inquilina da dor / Morada predileta / Na calada ela vem / Refém da vingança / Irmã do desespero / Rival da esperança / Pode ser causada por vermes e mundanas / E o espinho da flor / Cruel que você ama / Amante do drama / Vem pra minha cama, por querer / Sem me perguntar, me fez sofrer / E eu que me julguei forte / $\mathrm{E}$ eu que me senti / Serei um fraco quando outras delas vir / Se o barato é louco e o processo é lento / No momento, deixa eu caminhar contra o vento / O que adianta eu ser durão e o coração ser vulnerável? / O vento não, ele é suave, mas é frio e implacável / (É quente) Borrou a letra triste do poeta / (Só) Correu no rosto pardo do profeta / Verme, sai da reta

A lágrima de um homem vai cair / Esse é o seu B.O. pra eternidade / Diz que homem não chora / Tá bom, falou / Não vai pra grupo irmão, aí / Jesus chorou! (JESUS..., 2002, grifo nosso)

Como bem expressam os destaques do trecho, a poesia explora a imposição de ter que ser forte o tempo todo. Mais do que isso, a música inicia incitando a naturalização desse problema de ordem social e emocional que atinge, sobretudo, os sujeitos nascidos biologicamente do sexo masculino na sociedade ocidental. Aqui entra em questão também o debate de raça, inevitável no contexto apresentado no decorrer da música. Ao perguntar “O que adianta eu ser durão e o coração ser vulnerável?”, o interlocutor está questionando uma construção de masculinidade direcionada ao homem negro na sociedade ocidentalizada que estrutura o Brasil. Acontece que o ocidente outorga estigmas de força e resistência, o estereótipo do "durão", enquanto vulnerabiliza esse grupo social nos mais explícitos e nos mais sutis detalhes cotidianos encaminhados pelo racismo estrutural (ALMEIDA, 2018) - nesse primeiro momento da canção é citado o verso “deixa eu caminhar contra o vento", trecho também encontrado na canção Alegria, 
alegria de Caetano Veloso (ALEGRIA..., 1967)7. A construção da masculinidade negra no Brasil é tecida a partir da interiorização de estigmas negativos dirigidos ao homem negro na constituição deste sobre si mesmo (RIBEIRO; FAUSTINO, 2017). Entendemos que os estigmas negativos associados ao homem negro são assimilados por ele através da formação de seu ego (FREUD, 1996). Já o sentido geral de masculinidade formulado pelo ocidente é aspirado como ideal de ego e, ao passo que é uma construção branca, é alvo do ideal de ego do negro, mas que se torna um ego inalcançável a esses sujeitos como ressalta Santos (1990) em sua obra Tornar-se negro.

Ribeiro e Faustino (2017) contribuem significativamente para esse debate, sobretudo à luz de uma análise específica sobre a arte dos Racionais MC's. Os autores mapearam bibliografias sobre o assunto e apontaram para a necessidade de trabalhar esse tema de maneira prudente, a fim de não partir somente da ideia de que esse homem negro e sua masculinidade são frutos, pura e simplesmente, da colonização. Há de se entender que essa seria uma conclusão rasa que somente levaria à reprodução de ideários racistas, posto que esse sujeito não se reduz à construção social que lhe foi imposta pelo ocidente, e é, necessariamente, muito mais complexo do que isso. De acordo com esses autores, a origem da ideia de que o homem negro é um problema, tal como do temor geralmente associado à sua imagem, é um produto externo ao mesmo. Isso é, a masculinidade negra construída socialmente e comumente aceita como dogma de si mesmo pelos homens negros, é um conceito externo a este, elaborado pela sociedade que o estigmatiza e marginaliza a todo tempo.

Um bom exemplo de como se define essa masculinidade negra no imaginário social é abordado por Dalcastagnè (2008), que trata da objetificação, coisificação e animalização do homem negro na cultura brasileira através da literatura contemporânea. A autora costura análises como a de que, ainda hoje, esse homem negro, "[...] diante da mulher branca continua sendo representado como o animal sujo cobiçado pela fêmea depravada - como nos contos "O negro", de Dalton Trevisan (1968) e "O negro e as cercanias do negro", de Haroldo Maranhão (2001)" (DALCASTAGNÈ, 2008, p. 98). Convém situar no tempo e no espaço a situação vivida por Fanon, e por ele relatada no

\footnotetext{
7 Marco inicial do movimento Tropicalismo.
} 
livro "Pele negra, máscaras brancas" sobre o temor construído acerca da imagem do homem negro:

\begin{abstract}
“Mamãe, olhe o preto, estou com medo!" Medo! Medo! E começavam a me temer. Quis gargalhar até sufocar, mas isso tornou-se impossível.

Eu não aguentava mais, já sabia que existiam lendas, histórias, a história e, sobretudo, a historicidade que Jaspers havia me ensinado. Então o esquema corporal, atacado em vários pontos, desmoronou, cedendo lugar a um esquema epidérmico racial. No movimento, não se tratava mais de um conhecimento de meu corpo na terceira pessoa, mas em tripla pessoa. No trem, ao invés de um, deixavam-me dois, três lugares. Eu já não me divertia mais. Não descobria as coordenadas febris do mundo. Eu existia em triplo: ocupava determinado lugar. la ao encontro do outro... e o outro, evanescente, hostil mas não opaco, transparente, ausente, desaparecia. A náusea [...]. (FANON, 2008, p. 105, grifos do autor)
\end{abstract}

Posto isso, mais uma questão pode ser assinalada no sentido da semelhança entre Jesus e o interlocutor. Jesus Cristo não apenas também é um homem que chora, mas é um sujeito não branco, apesar de embranquecido. Embora as construções sociais de racialização vigentes não valham para o período de Jesus, sua origem étnica e seus traços fenotípicos o estigmatizavam como o não dominante, semelhantemente ao que hoje significa a posição de um sujeito não branco em nossa sociedade. A canção, então, desmistifica a ideia hegemonizada de um deus branco e europeu (BEREZOSCHI, 2017).

Aqui, temos uma ilustração do quadro sistematizado na canção através da questão do colorismo, debate desenvolvido em nosso país, conhecido pela miscigenação (SILVA, 2017). O termo pardo indica uma posição de não lugar delicada na sociedade brasileira. A ordem racial sobre a qual o Brasil funciona tende a tensionar, justamente, o processo de identificação político-social do sujeito que pode assumir a tarefa de se tornar negro, politicamente falando (SOUZA, 1990). Entretanto, apesar das acaloradas e múltiplas discussões possíveis que estenderiam desnecessariamente nossa reflexão, optou-se por pontuar de forma conclusiva o fato de que o negro (preto ou pardo) no Brasil não goza de privilégios. Independentemente da posição social em que se encontre, esse corpo negro é fruto de uma oportunidade (de oportunidades ou da falta delas) encontrada(s) 
(ou não) em seu percurso, dada a estrutura genocida na qual está inserido. Da mesma forma, o sujeito branco que carece de privilégios sociais comuns àqueles que possuem o mesmo fenótipo é resultado de um 'erro de percurso' (SANTOS, 2015; SANTOS, 2003). Isso porque nossa sociedade possui lugares rigidamente definidos por origem e/ou cor de pele. No caso dos negros, trata-se de oportunidade e não de privilégios, pois o conceito de privilégio pressupõe uma regra estrutural da ordem societária, a qual não é dada àqueles sujeitos de pele melaninada (HARRIS, 1993).

\section{Segunda parte: o novo dia}

Nesta parte da letra do rap, o autor se volta para pensar o futuro, o que, diante das condições que limitam perspectivas otimistas, pode produzir angústia. Vê-se, então, uma ansiedade através do que pode ser interpretado como sofrimento psíquico do interlocutor. O mesmo começa apontando para algumas conclusões próprias sobre o que observa.

Porra, vagabundo / Ó, vou te falar / Tô chapando / Eita, mundo bom de acabar! / O que fazer quando a fortaleza tremeu / $\mathrm{E}$ quase tudo ao seu redor / Melhor, se corrompeu?

'- Epa, pera lá! Muita calma, ladrão / Cadê o espírito imortal do Capão? / Lave o rosto nas águas sagradas da pia / Nada como um dia após o outro dia!'

Que?

'- Quem sou eu, seu lado direito / Tá abalado? Por que veio? / Nego, é desse jeito!'

Durmo mal, sonho quase a noite inteira / Acordo tenso, tonto e com olheira / Na mente, sensação de mágoa e rancor / Uma fita me abalou na noite anterior. (JESUS..., 2002, grifo nosso)

Nessa parte, o interlocutor reflete sobre o que fazer nos casos complexos que relata durante toda a poesia, todos assuntos que parecem não ter saída. Aqui seu alterego é apresentado como seu "lado direito" e aparece como um segundo interlocutor, uma segunda voz que lhe responde que a periferia é uma espécie de solução para as questões postas à tona. No trecho "Cadê o espírito imortal do Capão", o interlocutor 
justifica sua perspectiva alegando que as periferias prevalecem fortes apesar dos inúmeros problemas nelas e por elas vivenciados. Isso por si só se aparta da concepção popular de que as periferias são um problema, uma questão a ser resolvida. No ocidente, o Outro é sempre uma questão, sua autonomia e individualidade são domadas, controladas através do processo de coisificação (FANON, 2008). É isso que mantém a hegemonia e a supremacia branca. Por isso, uma conclusão como essa é potencialmente revolucionária: se as periferias são, na verdade, a solução e não o problema, a lógica hegemônica foi descartada.

No mais, a menção de Mano Brown ao Capão Redondo, ou ao "espírito imortal do Capão", comumente narrado em suas canções, serve para expor a periferia como uma referência onde buscar forças para continuar, conforme sugere o segundo interlocutor, ou seu alter-ego. O Capão Redondo representa, portanto, todas as favelas e seu potencial fortalecedor, associando força e orgulho da origem periférica. Nesses termos, encontramos o verso que dá nome ao álbum no qual se insere a canção aqui analisada, Nada como um dia após o outro dia, também encontrado no famoso trecho da música Jorge Maravilha, de Chico Buarque (JORGE..., 1973).

A grande questão aqui é entender para quem as periferias são soluções e para quem elas são um problema. Para a população que encontra nela um meio de sobrevivência e alguma dignidade frente à desumanização de seus corpos, majoritariamente negros, ela é a grande solução, lugar de acolhimento e de pertencimento. Para uma pequena parcela, ela é apenas sinônimo de problemas sociais que geram criminalidade e insegurança pública. Todavia, o que vale de fato refletir nesse ponto é se realmente, para estes últimos, há o interesse de solucionar isso que eles entendem como problema e se, ainda para estes, o problema (as favelas) não gera nenhum tipo de lucro.

Para essa parcela que vê nas periferias uma questão, desfazer o problema significaria reestruturar uma sociedade desigual que os privilegia e os coloca no topo da pirâmide societária; isto é, para eles, que, em geral, têm poder para decisões importantes, a elaboração de políticas públicas para as favelas está unilateralmente relacionada ao lucro (SOUZA, J., 2018). Por isso, para os sujeitos lidos como elite e envoltos em uma 
mentalidade calcada no racismo estrutural, essa é uma oportunidade de fomentar a necessidade de segregação social, mantendo, assim, os interesses hegemônicos da elite brasileira (SOUZA, J., 2018).

Essa perspectiva acerca da lógica de atuação da elite brasileira também foi abordada em uma canção de outro estilo musical, popularizado no país no final da década de 1990, o axé, pelo grupo baiano As Meninas, que fez sucesso narrando as desigualdades sociais através de uma linguagem acessível, capaz de chegar a sujeitos marginalizados no país. A música Xibom Bombom, lançada em 1999 pelo grupo, trouxe uma forte crítica social, fazendo, entre outros apontamentos, a seguinte menção, capaz de explicar e sintetizar perfeitamente o parágrafo acima: "Onde o rico fica cada vez mais rico / E o pobre cada vez mais pobre / E o motivo todo mundo já conhece / É que o de cima sobe e o de baixo desce" (XIBOM..., 1999).

Entretanto, as palavras positivas do segundo interlocutor não são suficientes, talvez apenas amenizem os sintomas de um sofrimento psíquico mais profundo e não essencialmente individual, mas justamente coletivo. O primeiro interlocutor coloca que não consegue dormir e não confia em um outro dia porque, para ele, os dias não passam, são todos iguais e problemáticos. Isso está associado à esperança por um outro dia, um dia que possa ser melhor do que o presente, e não simplesmente mais um dia qualquer, pois mais um dia como todos os outros vividos no passado e no presente não basta: espera-se pelo novo dia. A ansiedade por um novo dia é a espera por melhorias e aponta para um quadro de possível sofrimento psíquico decorrente das transformações que não podem vingar em um cenário para o qual tais mudanças, necessariamente, envolveriam a revisão de uma estrutura sobre a qual também se assenta a sociedade branca e elitizada, ou seja, a da assimetria e a da desigualdade.

Os sintomas desse sofrimento psíquico compartilhado por toda uma coletividade vulnerabilizada se associam não apenas à ansiedade por um chamado "futuro melhor", mas, sobretudo, à frustração da certeza de que as oportunidades são quase nulas na realidade periférica vivenciada pelo interlocutor. Ciente de uma estrutura que não se mostra porosa à transformação, cristaliza-se um sujeito que, para sobreviver, deve aceitar 
passivamente seu cenário de inscrição social, inclusive o sofrimento decorrente do reconhecimento da possível imutabilidade desse cenário.

\section{Terceira parte: a capilaridade do racismo no Brasil}

Nesse momento do rap, entram outros personagens no diálogo que se constrói através de uma ligação telefônica, na qual problemas são tratados de maneira mais geral, desde o que se define por racismo ao que se entende por negritude (CÉSAIRE, 2010). Por negritude, definimos uma exigência ontológica do sujeito negro animalizado e coisificado que, conforme concebe Césaire (2010), trata-se de uma consciência identitária específica dos sujeitos negros. Esse conceito foi cunhado pela primeira vez em 1935, por Aimé Césaire na edição de número 3 da revista L'étudiant noir em Paris, com o objetivo de desconstruir e inoperar o conceito de raça através de uma práxis e um pensamento situados em um terreno em que ideias e práticas se movimentam para reverter o racismo (CÉSAIRE, 2010).

Alô!

Aí! / Dorme, hein, doidão! Mil fita acontecendo e cê ai?

Que horas são?

Meio dia e vinte, ó / A fita é o seguinte, ó / Não é esqueirando não, ó / Fita de mil grau / Ontem eu tava ali de CB, no pião / Com um truta firmezão / Cê tem que conhecer / Se pã, cê liga ele / Vai saber, de repente / Ele fazia até um rap num passado recente

Aham

Vai vendo a fita / Cê não acredita / Quando tem que ser, é, jão. Pres'tenção / Vai vendo: parei pra fumar um de remédio / Com uns muleque lá e pá, trafica nos prédios / Um que chegou depois, pediu pra dar uns 2 / Logo um patrício, ó, novão e os carai / Fumaça vai, fumaça vem / ele chapou o coco / Se abriu que nem uma flor, ficou louco / Tava eu mais dois truta e uma mina / Num Tempra prata show filmado, ouvindo Guina / Ih, o bico se atacou, ó! / Falou uma pá do cê

Tipo o que?

'- Esse Brown aí é cheio de querer ser / Deixa ele moscar, vir cantar na quebrada / Vamo ver se é isso tudo quando ver as quadrada / Periferia nada, só pensa nele mesmo / Montado no dinheiro e cês aí no veneno?' 
E a cara dele, truta! / Cada um no seu corre / Tudo pelas verde / Uns matam, outros morrem / Eu mesmo, se eu catar, a boa numa hora dessa / Vou me destacar pro outro lado depressa / Vou comprar uma house de boy, depois alugo / Vão me chamar de senhor, não por vulgo

'- Mas pra ele só a Zona Sul que é a pá / Diz que ele tira nós, nossa cara é cobrar / O que ele quiser nós quer, vem que tem / Porque eu não pago pau pra ninguém?'

E eu, só registrei, né? Não era de lá / Os mano tudo só ouviu, ninguém falou um $A$

Quem tem boca fala o que quer pra ter nome / Pra ganhar atenção das mulher e/ou dos homem / Amo minha raça, luto pela cor / O que quer que eu faça é por nós, por amor / Não entende o que eu sou, não entende o que eu faço / Não entende a dor e as lágrimas do palhaço. (JESUS..., 2002, grifo nosso)

Esses versos, que classificamos como a terceira parte, iniciam com um diálogo ao telefone que pode ser organizado em dois momentos: (1) a narrativa sobre um acontecimento que envolve um dos interlocutores, no caso, representado por Mano Brown, e (2) uma espécie de monólogo do primeiro interlocutor. No diálogo, explana-se uma acusação de que existem pessoas difamando o primeiro interlocutor, Mano Brown, por meio de alegações de apropriação da cultura local. Aqueles que o difamam, interrogam se realmente Mano Brown se importa com a favela, ou se ele a tem somente enquanto um meio de fazer dinheiro. Então, no segundo momento, ele se defende e refuta a hipótese formulada por desconhecidos, afirmando não ser ganancioso ou mesquinho por ter como objetivo sair da miséria, meta, inclusive, aponta ele, desejada por todas as vítimas da miséria.

Em seu monólogo, Mano Brown ainda se coloca em defesa da favela e de seus valores, por mais que entenda que sair dela é sinônimo de encontrar um pouco de paz. Um pouco, apenas um pouco, afinal, tal como é exposto em Negro Drama (NEGRO..., 2002): "o dinheiro tira um homem da miséria/ Mas não pode arrancar de dentro dele a favela"; em todo lugar que ele vai, sua origem é lembrada, o tratamento dado a ele não condiz com sua conta bancária, mas com sua raiz periférica e a cor de sua pele, ressaltando a estrutura e a capilaridade do racismo à brasileira (ALMEIDA, 2018). 
O panorama periférico, e sobretudo o Capão Redondo, bairro de Mano Brown, que o formou tanto musicalmente, como espiritualmente, enquanto artista, é central nessa parte, assim como a sua relação com as pessoas. A música apresenta um homem favelado que se coloca como sujeito e não como o Outro de Fanon (2008), não aceitando qualquer subjugação, ainda que limitado às condições sociais quando o mesmo fala "Vão me chamar de senhor, não por vulgo". E nesse ponto, encaminha-se também para uma expressão de sua negritude, reafirmando que o "ser negro" é um ato político (SOUZA, N., 1990; CÉSAIRE, 2010).

Porém, a negritude não faz sentido para todos. Ao seu redor, muitos não o entendem. Afinal, prega-se no Brasil o caminho da denegação às raízes africanas (GONZALEZ 1988), fazendo com que alguns não entendam a luta negra, na qual o interlocutor se coloca. Isso gera, além do sentimento de incompreensão, o de desvalorização, o que causa a angústia identificada no trecho "Não entende o que eu sou, não entende o que eu faço / Não entende a dor e as lágrimas do palhaço”. Essa mesma questão é apontada em Fórmula Mágica da Paz, que aponta para a inimizade entre iguais que, em ambos os casos, são os negros periféricos (OLIVEIRA; SEGRETO; CABRAL, 2013). A partir daí, seu "lado direito", o segundo interlocutor, retorna enquanto uma voz inconsciente para repreendê-lo, questionando sua angústia, reforçando que "[...] é desse jeito!" (OLIVEIRA; SEGRETO; CABRAL, 2013).

Para complementar, Berezoschi adiciona a essa parte interpretações bíblicas e a questão do estado de exceção permanente do qual os sujeitos de periferias são vítimas.

Jesus chorou mostra a dor que o rapper carrega no momento em que percebe que seu sucesso é motivo de inveja dos outros manos dentro da periferia. O lugar do rapper, de líder, apoiado por mais de 50 mil manos é o mesmo lugar cristão, de liderança política, com seguidores ao redor do mundo. E assim como Judas invejou Jesus e - apenas por trinta moedas o irmão corrompeu, o Zé Povinho inveja o rapper. Inveja sua posição de prestígio enquanto líder, que conquistou novas coisas e criou um caminho de glórias. Na periferia, a disputa por poder e prestígio é recorrente, mesmo que esse poder seja ["apenas"] ter um carro melhor. Mas esse tipo de poder não é soberano, ele apenas faz parte do jogo de poder que acontece no Estado moderno, no estado de exceção permanente, no qual o poder soberano é aquele que decide quem pode 
morrer e quem pode viver, ou que faz morrer e deixa viver. [...] Todos somos matáveis e insacrificáveis e, dentro da periferia, essas mortes tornam-se mais explícitas, já que o Estado, costumeiramente, entra apenas na forma de polícia, que mata e que contribui com a violência do lugar. (BEREZOSCHI, 2017, p. 83, grifos nossos)

\section{Quarta parte: o lugar destinado aos filhos do ventre negro}

Aqui, voltam o indivíduo e o reforço da sua condição de sujeito no contexto racista e de segregação social vividos por ele. Essa parte traz à tona a construção do interlocutor como homem negro e periférico, desde sua criação a sua concepção de si mesmo e de seu "lugar" no mundo.

Mundo em decomposição por um triz / Transforma um irmão meu num verme infeliz / E a minha mãe diz:

'- Paulo, acorda! Pensa no futuro que isso é ilusão / Os próprio preto não tá nem aí com isso não / Ó o tanto que eu sofri, o que eu sou, o que eu fui / A inveja mata um, tem muita gente ruim'

Pô, mãe! Não fala assim que eu nem durmo / Meu amor pela senhora já não cabe em Saturno / Dinheiro é bom / Quero, sim, se essa é a pergunta / Mas a dona Ana fez de mim um homem e não uma puta! / Ei, você, seja lá quem for / Pra semente eu não vim / Então, sem terror / Inimigo invisível, Judas incolor / Perseguido eu já nasci, demorou / Apenas por 30 moeda o irmão corrompeu / Atire a primeira pedra quem tem rastro meu / Cadê meu sorriso? Onde tá? Quem roubou? / Humanidade é má e até Jesus chorou / Lágrimas, lágrimas / Jesus chorou. (JESUS..., 2002, grifo nosso)

É possível perceber que a relação do homem ambientado à favela volta a ser central na música e, bastante angustiado, o interlocutor afirma o quanto essa realidade pode transformar um homem. Nesse trecho, a canção fica mais pessoal e, portanto, mais profunda através também da presença da figura da mãe, que surge como aquela mais velha, detentora de saberes ancestrais, mas sobretudo como uma mãe preocupada com o futuro de seu filho, o interlocutor da música. A preocupação da mãe diz respeito ao que ele pode vir a passar, tendo como referência seu próprio passado na condição de sujeito negro. Todavia, o interlocutor a retruca, argumentando que sua personalidade teimosa é fruto da criação dada por ela, a deixando sem respostas. Aqui, cabe apontar para uma 
perspectiva matriarcal, também presente em Negro Drama e muito comum em famílias negras (pretas e pardas) e periféricas no Brasil.

A questão do matriarcado no Brasil pode ser entendida a partir de Miranda e Portilho (2018), que apontam que a família constituída a partir da mulher negra na diáspora brasileira se revela um potente meio de manutenção das tradições culturais africanas $^{8}$ que vieram para o Brasil no contexto da escravização. As autoras posicionam essa mulher negra no centro da organização e gestão familiar nas periferias, inclusive expondo dados estatísticos que explanam que o número de mulheres que chefiam casas no Brasil dobrou em um período de apenas dez anos (1995-2005). Essa análise também é defendida por Berezoschi (2017), que coloca a mulher como figura central da família periférica, tendo como base, inclusive, as músicas dos Racionais MC's enquanto fontes que deixam essa realidade bem nítida e explicada no que tange ao seu campo empírico.

Na família periférica centrada na mãe, a mulher não é sinônimo de esposa, o que não é compreendido pelo ocidente (MIRANDA, PORTILHO, 2018). Muitas análises acadêmicas acerca das periferias e dessas famílias têm resultados questionáveis justamente pela tentativa de submetê-las a uma ordem externa, a um padrão ocidental possivelmente também revelado pelos pesquisadores desse contexto. Afinal, se o masculino ${ }^{9}$ negro é tão prejudicado o tempo todo pela maafa ${ }^{10}$ (ANI, 1994), em um perfeito movimento do sistema opressor, como essas famílias persistem somente com a força feminina, a qual é subestimada pela lógica branca e elitista?

\footnotetext{
${ }^{8}$ Quanto à compreensão que associa famílias periféricas à ordem societária de tradições africanas, colocam Miranda e Portilho (2018, p. 5): "Esta centralidade alude alguns fatores presentes nas sociedades africanas vindas para o Brasil, o mais importantes desses, é a forma em que a mulher africana concebida como unidade de análise do feminino. Notadamente, sua condição está associada a uma visão de mundo metafísica, onde ela representa e detém domínio sobre a relação sociedade-natureza, condição esta que atribui-Ihe o domínio do conhecimento e gestão praticados no âmbito social e espiritual".

${ }^{9}$ Base da família ocidental patriarcal.

${ }^{10} \mathrm{O}$ desastre sofrido pelos africanos no último movimento afro-diaspórico concluído. É oportuno acentuar que o termo em tela não se limita à escravidão, mas à colonização e às outras violências sofridas e que se perpetuam nos dias atuais com os africanos e seus descendentes (ANI, 1994). O termo foi cunhado pela antropóloga Marimba Ani, que conceituou a palavra, de origem kiswahili, em seu livro "Yurugu" em 1994.
} 
Para aqueles cujas favelas são sinônimo de problema e lucro (SOUZA, J., 2018), conforme destacado, essas famílias são tidas como "desestruturadas" "11, haja vista que não seguem o padrão hegemonicamente imposto, o que ocorre devido às violências as quais são submetidas em decorrência do genocídio (NASCIMENTO, 2016). O próprio emprego, inclusive no senso comum, da expressão família “desestruturada" sugere a ideia de uma estrutura ideal, composta por pai, mãe e filhos, normatizada a partir de critérios externos ao que observamos, sobretudo nas periferias. A desestruturação ou o desajuste, a partir desse argumento, revelariam, portanto, a não conformidade com uma norma ocidental, branca e elitizada. Todavia, nesse ponto, o ocidente se esquece da figura de Maria, uma mulher importante de sua cultura religiosa predominante (o cristianismo). Nesse sentido, Dona Ana, mãe de Mano Brown (o interlocutor da poesia), pode ser associada à Maria Madalena que representa, nesse caso, mais uma vítima de uma sociedade machista e excludente que a subjugava enquanto sujeito marginalizado da sociedade em que vivia.

O fruto da força de Dona Ana é a gestão familiar matriarcal das configurações familiares da diáspora, a qual Miranda e Portilho (2018) conceituaram através do termo GMATER $^{12}$. As teorias feministas, que hegemonizam os estudos de família e gênero, redefiniram os conceitos sobre o matriarcado africano e buscam ainda hoje negar a existência dessas organizações familiares pautadas em mulheres poderosas, autônomas e não brancas (MIRANDA; PORTILHO, 2018). Todavia, a voz entoada pelos Racionais MC's a fim de homenagear Dona Ana, reforça o inquestionável sistema GMATER (MIRANDA; PORTILHO, 2018) institucionalizado nas famílias periféricas e, sobretudo, negras.

Ainda que de maneira mais sutil, a cor da pele e o racismo entram na canção que aponta para um "Judas incolor". Os últimos versos dessa quarta parte se voltam para referências bíblicas, apresentando Judas como inimigo e reforçando o choro de Jesus, que chora diante da maldade entre os humanos, os mesmos pelos quais ele se sacrificou e

\footnotetext{
11 Há menos de dois anos, o atual vice-presidente da República declarou que famílias sem a presença de um homem são "fábricas de desajustados" (RAMIL, 2018).

12 Termo cunhado pelas autoras "que sistematiza e conceitua os princípios fundamentais da gestão nos sistemas matriarcais africanos e os traz para a realidade e demandas do cotidiano do povo negro no país" (MIRANDA; PORTILHO, 2018, p. 7).
} 
salvou. Também discreto, o verso: "Mas a dona Ana fez de mim um homem e não uma puta!", é comumente problematizado e denunciado como uma fala de caráter machista (BEREZOSCHI, 2017; CABRAL, 2019). Todavia, uma análise mais profunda do contexto abordado na música nos permite ir além, compreendendo a fala de outras maneiras, pois tudo depende da semântica atrelada à palavra "puta".

Assim sendo, o termo "puta" não necessariamente é oposto de homem, ou tem conotação simplesmente sexual, e sim está popularmente associado a alguém que se vende por pouco (BEREZOSCHI, 2017). O retorno financeiro da prostituição não condiz com seus desgastes para a maioria $(89 \%)^{13}$ daquelas inseridas nesse contexto (SEMPREVIVA ORGANIZAÇÃO FEMINISTA, 2013). Assim, pensar em não ser uma "puta" é ir além, é ultrapassar as expectativas formuladas para o sujeito negro e periférico. No mais, como mencionou o próprio Mano Brown no programa Roda Viva, da TV Cultura (2007), os direcionamentos machistas em suas músicas são resultados diretos do que se vê na sociedade, na medida em que o rap retrata as problemáticas sociais e, no caso das letras dos Racionais MC's, muitas retratam suas vivências e experiências pessoais. No entanto, cabe mencionar que o próprio Mano Brown (2018), em entrevista ao Le Monde Diplomatique Brasil ${ }^{14}$, repensa o viés machista e sexista de sua obra, pede perdão às mulheres e relata ter mudado o pensamento, pois, segundo o artista, "não vale a pena só para rimar falar essas coisas" (referindo-se às músicas com teor machistas e sexistas) e relata ter respeito pelas mulheres e o que essas representam socialmente para ele.

Face ao exposto, convém ressaltar que da mesma forma que Ribeiro e Faustino (2017) interpretaram Joel Rufino dos Santos e Wilson do Nascimento Barbosa (1994) em suas comparações sobre mulheres brancas e negras a carros, sendo as mulheres brancas comparadas a carros modelo monzas e as mulheres negras a carros modelos fuscas, pois segundo os autores (SANTOS; BARBOSA, 1994), mulheres negras possuíam status socialmente inferiores ao das mulheres brancas, entendemos essa poesia como uma mensageira da mentalidade sexista existente na sociedade e não como a mensagem machista em si.

\footnotetext{
${ }^{13}$ Dado referente a pesquisa de Farley et al. (2003).

${ }^{14}$ Entrevista realizada em dezembro de 2017.
} 
Não menos importante, e em diálogo com o restante da canção, também os últimos versos evidenciam a falta de perspectiva do negro no contexto da maafa (ANI, 1994). Dentro dessa questão, há ainda a dúvida sobre em quem é possível confiar, dada a vivência diaspórica em que a discriminação vem de berço pela cor da pele e origem, não restando muitas outras opções ou mesmo aspirações, soma que resulta também no sofrimento psíquico apontado em toda a letra. É a percepção de que "ser negro numa sociedade racista não é apenas ter outra cor, é ter outra perspectiva social (nos termos de Iris Marion Young), outra experiência de vida, normalmente marcada por alguma espécie de humilhação" (DALCASTAGNÈ, 2008, p. 98).

\section{Quinta parte: o vencedor}

A última parte é iniciada com uma possível alusão tanto às sirenes de uma viatura policial, como às cores do luminoso do nome de um hotel, representado pelo vermelho e azul, que dão entrada a este trecho. Aqui, nosso interlocutor traz à tona suas dores, ansiedades, individualidade, perspectivas e as condições que o fizeram ser quem é, as mesmas pelas quais é discriminado na sociedade. Ele ambienta o cenário em que se encontra para costurar as reflexões da música que terminam tal como seu início: a partir das lágrimas de um sujeito oprimido pela sociedade, seja esse Mano Brown ou Jesus Cristo.

Vermelho e azul, hotel / Pisca só no cinza escuro do céu / Chuva cai lá fora e aumenta o ritmo / Sozinho, eu sou agora o meu inimigo íntimo / Lembranças más vêm, pensamentos bons vai / Me ajude, sozinho eu penso merda pra carai / Gente que acredito, gosto e admiro / Brigava por justiça e paz, levou tiro / Malcolm X, Gandhi, Lennon, Marvin Gaye / Che Guevara, 2Pac, Bob Marley / E o evangélico Martin Luther King / Lembrei de um truta meu falar assim:

'- Não joga pérolas aos porco, irmão, joga lavagem / Eles prefere assim, cê tem de usar piolhagem!'

Cristo que morreu por milhões / Mas só andou com apenas 12 e um fraquejou / Periferia: corpos vazios e sem ética / Lotam os pagode, rumo à cadeira elétrica / Eu sei, você sabe o que é frustração / Máquina de fazer 
vilão / Eu penso mil fita, vou enlouquecer / E o piolho diz assim quando me vê:

'- Famoso pra carai, durão! Ih, truta! / Faz seu mundo, não, jão! A vida é curta / Só modelo por aí dando boi / Põe elas pra chupar e manda andar depois / Rasgar as madrugadas só de mil e cem / Se sou eu, truta, tem pra ninguém!'

Zé povinho é o cão, tem esses defeito / Quê? Cê tendo ou não, cresce os olhos de qualquer jeito / Cruzar, 'cê' arrebenta / De repentemente, vai, de ponto quarenta / Só querer, tá no pente / Se só de pensar em matar, já matou

Eu prefiro ouvir o pastor:

'-Filho meu, não inveje o homem violento / E nem siga nenhum dos seus caminhos?'

Lágrimas / Molha a medalha de um vencedor / Chora agora, ri depois / Aí, Jesus chorou. (JESUS..., 2002, grifo nosso)

Assim, o começo do fim denota um monólogo que exprime um momento de solidão e desespero do interlocutor devido à maldade da humanidade. Ele dá exemplo de pessoas em que ele acredita que lutaram por um mundo melhor e que foram assassinadas, justificando sua frustração. A falta e/ou o perdão dessas referências acusam o silenciamento de vozes marginalizadas como a dele, o que o deixa desesperançoso quanto às suas aspirações para o futuro, enquanto um sujeito de voz ativa ${ }^{15}$. Nesse momento, seu clamor é o mesmo de Bob Marley (REDEMPTION..., 1980) quando diz, em Redemption Song, "How long shall they will kill our prophets / While we stand aside and look?”16. Essa é também mais uma demonstração que expressa a semântica afetiva e política da negritude de Césaire (2010). Também acaba por indicar e reforçar a triste realidade e a naturalização de que corpos pretos e periféricos têm destino certo e imutável através da rigorosa falta de transformação social em nosso país.

Afirma ainda que "Cristo que morreu por milhões/ Mas só andou com apenas 12 e um fraquejou", para compreender esse trecho é necessário retomar a célebre entrevista de Mano Brown ao Programa Roda Viva, da TV Cultura (2007), onde, ao ser perguntado

\footnotetext{
15 Outra referência a uma canção dos Racionais MC's, trata-se de Voz Ativa, apresentada no álbum Escolha seu caminho (1992).

16 "Até quando eles matarão nossos profetas / Enquanto ficamos parados e olhamos?" (REDEMPTION..., 1980, tradução nossa).
} 
sobre sua religião, se declara evangélico. Tal apontamento é identificado em "Jesus Chorou" a partir do trecho "Eu prefiro ouvir o pastor"; Mano Brown (2007), na entrevista acima citada, relata ter nascido no Candomblé, e que Jesus não pregava a opressão e a perseguição religiosa e finaliza dizendo: “onde os evangélicos acertam: amar a Deus sobre todas as coisas" ${ }^{17}$. Tal menção permite compreender a diversidade religiosa existente nas periferias brasileiras, sobretudo enquanto espaços onde se estabelecem muitos terreiros de candomblé e igrejas evangélicas (GAIA; VITÓRIA; ROQUE, 2020; VELECI, 2017; TOLEDO; CASSAB, 2019).

A pauta que finaliza esses últimos versos persiste com uma das questões centrais abordadas na canção: de que forma o desespero e a miséria conseguem levar um homem a realizar más ações? Essa perspectiva de que a frustração é um caminho para os erros nos leva a questionar quem estipula o erro. O que é certo ou não, crime ou não, bom ou mau? E, acima de tudo, quem define esses conceitos? Qual o papel das vozes periféricas na definição desses conceitos? Não cabe aqui responder a essas colocações e sim fomentar a reflexão. Nesse caso, o interlocutor argumenta com tom de ironia uma possível resposta, ao trabalhar a ideia de que dinheiro não é solução para aqueles que têm sua cor e suas origens. Ele expõe que muitas pessoas acreditam que o dinheiro resolve tudo, mas não podem fazer dele um definidor desses conceitos de erro e crime, tão constantemente atrelados a sua figura, independentemente de seu poder aquisitivo. No eficiente sistema racista brasileiro, ter fama e dinheiro não é o suficiente para manter um negro favelado em paz. E é tanto por isso que ele conclui que é preciso aproveitar enquanto pode os benefícios do dinheiro.

Ainda, quando afirma "corpos vazios e sem ética", a canção faz menção à alienação (BEREZOSCHI, 2017); trata-se justamente daqueles que não o compreendem, na parte três. Além disso, esse trecho também problematiza a dita "trairagem entre manos": a violência interna entre os marginalizados, já tão violentados, aproveitando para ressaltar o quanto estes já são ameaçados por um mundo que os quer restritos às periferias (BEREZOSCHI, 2017).

\footnotetext{
${ }^{17}$ A passagem 'Amar a Deus sobre todas as coisas' pode ser encontrada em Mateus 22:36-40 (BíBLIA, 2008, p. 1491) e Deuteronômio 6:5 (BIBLÍA, 2008, p. 315).
} 
Voltando-se às lágrimas e ao debate acerca da fé, a música termina com mais uma referência bíblica e uma alusão à esperança. Todavia, preponderam a solidão e a culpa. Com evidente explanação de algum sofrimento psíquico, inclusive com sintomas patológicos, que foram apontados também ao longo de toda a letra, a canção começa e termina em lágrimas. Dentro disso, o interlocutor pede ajuda, reconhecendo que não está bem ("sozinho eu penso merda pra carai"), assumindo sua frustração e reforçando sua humanidade, tão incessantemente questionada e violada ao longo da história, através das lágrimas, pois, afinal, até Jesus chorou quando viveu entre os homens, conforme narram os registros bíblicos.

Nesse momento final, as lágrimas não são mais apenas pela dor, mas simbolizam as lágrimas daquele que venceu o novo dia, que sobrevive mesmo com todos os percalços cotidianos e carrega, merecidamente, uma medalha (BEREZOSCHI, 2017). A mensagem final que fica é que, mesmo que chore no presente, é possível rir depois de tudo, no momento em que se tornar um vencedor, quando carregar a medalha. Para isso, é preciso encarar esse mundo todos os dias e ter coragem para o novo. Isso não necessariamente diz respeito a grandes vitórias, mas viver o dia sem a frustração da espera de algo que nunca chega (a ansiedade exemplificada na parte dois) por si só já faz do novo dia, de fato novo, e do sujeito periférico sobrevivente a tudo, um vencedor.

Outra leitura possível é a de que esse estado de vitória se estruture sobre a própria condição de uma sociedade assentada na pretensa meritocracia, como se as transformações sociais não se sustentassem em ações coletivas, mas em ideações individuais, em esforços de cada sujeito, de modo isolado, o que é representado pela ascensão social de Mano Brown ao se tornar famoso. O lugar almejado, o do vitorioso, pode remeter ao que a sociedade contemporânea legitima, com pouco ou nenhum espaço para aquele que perde, que não corresponde aos critérios, que não chega, de fato, ao lugar reservado ao vitorioso. Associando-se esse não lugar a dificuldades individuais, desconstrói-se a possibilidade de resistência coletiva, de uma resposta grupal a essa estrutura.

Assim, a busca pela vitória parece funcionar como uma falácia, reforçando uma estrutura sólida, à qual, individualmente, não se pode responder. Qualquer vitória 
individual, nesse sentido, embora possa ser celebrada como uma exceção, reafirma a condição mais ampla e que não permite que esse itinerário seja percorrido pelos demais ou por muitos. Afinal, em uma estrutura capitalista sedimentada na assimetria, a igualdade de oportunidades para a mudança social seria um contrassenso.

\section{Considerações finais}

Ao final do percurso analítico, reafirma-se que Jesus Chorou é uma obra significativa para os debates acadêmicos no âmbito das relações de raça, gênero, classe e religiosidade, assim como no que tange à Psicologia Social e à necessidade de uma perspectiva mais abrangente sobre a ordem societária e a marginalização social. A canção também representa a potência da arte enquanto encaminhadora e desenhista dessas pautas. A partir da letra de Jesus chorou, podemos concluir as muitas semelhanças entre Jesus e o sujeito periférico representado pelo interlocutor Mano Brown. Segundo Berezoschi (2017), todo poeta e/ou MC tem um pouco de Jesus em si porque, em sua missão de ser um profeta, o filho do deus cristão precisava ser também um bom poeta para transmitir bem sua mensagem ao público.

As condições de desigualdades, violências e discriminações sofridas por esses sujeitos periféricos se contrapõem ao constructo social de masculinidade negra, a qual requer a imagem do negro imbatível, forte e resistente a tudo, o que, por consequência, o leva à interiorização de um ideário masculino prejudicial para si mesmo. Logo, percebese esse sujeito periférico com a saúde mental perturbada e um evidente sofrimento psíquico em seu cotidiano.

A música dos Racionais MC's, portanto, aproxima o sujeito periférico da imagem de Jesus ao apontar essas semelhanças, unindo um sujeito amado (Jesus) a sujeitos odiados (sobretudo homens negros e favelados) na sociedade em que vivemos. A espinha dorsal de toda essa reflexão está na ideia de um Jesus que chora e então se associa aos sujeitos marginalizados, como o interlocutor da canção, encaminhando-os para a consequente humanização desse corpo preto periférico. Ao passo que esse sujeito negro se percebe humanizado, após séculos de coisificação e animalização de sua 
imagem, é possível que entrem em evidência expressões de sua negritude (CÉSAIRE, 2010).

Em suma, Jesus chorou justamente pelas mazelas em que sua posição o colocou, Jesus chorou porque sofreu em condições não privilegiadas, e esse mesmo Jesus choraria hoje, pois sofreria junto ao interlocutor, vivendo os desafios de um sujeito não branco, dado seu propósito de vir ao mundo na posição de oprimido. Assim, essa interpretação do choro de Jesus dá o aval, a autorização necessária para esse homem chorar.

\section{Referências}

ALEGRIA, alegria. Intérprete: Caetano Veloso. Compositor: C. Veloso. In: CAETANO Veloso. Intérprete: Caetano Veloso. Philips Records, 1967. 1 disco vinil, lado A, faixa 4 (1min.32seg.).

ALMEIDA, Silvio Luiz de. O que é racismo estrutural? Belo Horizonte: Letramento, 2018.

ANI, Marimba. Yurugu: an african-centered critique of european cultural thought and behavior. Trenton: Africa World Press, 1994.

ARAÚJO, Ana Carolina Palma de. O direito por outras vozes: reflexões críticas a partir da música de Racionais MC's e Bezerra da Silva. 2013. 252p. Monografia (Graduação em Direito) - Universidade de São Paulo, Ribeirão Preto, 2013.

BEREZOSCHI, Ellen. $O$ bandido do céu: uma leitura da performance de Racionais MC's. 2017. 124f. Dissertação (Mestrado em Literatura) - Universidade Federal de Santa Catarina, Florianópolis, 2017.

BÍBLIA, A. T. Deuteronômio. In: BÍBLIA. Sagrada Bíblia Católica: Antigo e Novo Testamentos. Trad. José Simão. São Paulo: Sociedade Bíblica de Aparecida, 2008. p. 302366.

BÍBLIA, N. T. Hebreus. In: BÍBLIA. Sagrada Bíblia Católica: Antigo e Novo Testamentos. Trad. José Simão. São Paulo: Sociedade Bíblica de Aparecida, 2008. p. 1847-1867.

BÍBLIA, N. T. João. In: BíBLIA. Sagrada Bíblia Católica: Antigo e Novo Testamentos. Trad. José Simão. São Paulo: Sociedade Bíblica de Aparecida, 2008. p. 1609-1656. 
BÍBLIA, N. T. Lucas. In: BÍBLIA. Sagrada Bíblia Católica: Antigo e Novo Testamentos. Trad. José Simão. São Paulo: Sociedade Bíblica de Aparecida, 2008. p. 1545-1609.

BÍBLIA, N. T. Mateus. In: BÍBLIA. Sagrada Bíblia Católica: Antigo e Novo Testamentos. Trad. José Simão. São Paulo: Sociedade Bíblica de Aparecida, 2008. p. 1445-1507.

BROWN, Mano. Roda Viva: Mano Brown: 2007. Publicado pelo canal Roda Viva. [S.I.: s.n.], 25 set. 2007.1 vídeo (85 min). Disponível em:

https://www.youtube.com/watch?v=laQWmNkqkSg. Acesso em: 24 mar. 2020.

BROWN, Mano. Mano Brown, um sobrevivente do inferno: entrevista completa. Publicado pelo canal Le Monde Diplomatique Brasil. [S.I.: s.n.], 27 fev. 2018.1 vídeo (21 min). Disponível em: https://www.youtube.com/watch?v=U_OsF4y4zuY. Acesso em: 30 ago. 2020.

CABRAL, Igor H. S. Por via das dúvidas, o machismo: uma análise do topos misógino na obra dos Racionais MC's. 2019. 64f. Trabalho de Conclusão de Curso (Graduação em História) - Universidade Federal de Santa Catarina, Florianópolis, 2019.

CÉSAIRE, Aimé. Discurso sobre a negritude. In: MOORE, Carlos. (org.) Belo Horizonte: Nandyala, 2010. v. 3. (Coleção Vozes da Diáspora Negra).

CICONELLO, Alexandre. O desafio de eliminar o racismo no Brasil: a nova institucionalidade no combate à desigualdade racial. In: GREEN, Duncan. (org.). From poverty to power: how active citizens and effective states can change the world. London: Oxfam, 2008. (From Poverty to Power Case Study).

DALCASTAGNÈ, Regina. Entre silêncios e estereótipos: relações raciais na literatura brasileira contemporânea. Estudos de Literatura Brasileira Contemporânea, Brasília, n. 31, p. 87-110, jan./jun. 2008.

FANON, Frantz. Pele negra, máscaras brancas. Trad. Renato da Silveira. Salvador: EDUFBA, 2008. 194p.

FARLEY, Melissa. et al. Prostitution and trafficking in nine countries: an update on violence and posttraumatic stress disorder. In: FARLEY, Melissa. Prostitution, trafficking and traumatic stress. Binghamton: Haworth Press, 2003. p. 33-74.

FERNANDES, Cintia Sanmartin; HERSCHMANN, Micael; GUTIERREZ, Gabriel. Entre o corte da espada e o perfume da rosa: uma estética da existência no rap dos Racionais Mc's.

Cadernos de Estudos Culturais, Campo Grande, v. 1, p. 43-58, 2016.

FREYRE, Gilberto. Casa grande \& senzala. São Paulo: Global, 2005. 
FREUD, Sigmund. El yo y el ello. In: FREUD, Sigmund. Obras completas. Buenos Aires: Amorrortu, 1996. v. 19.

GAIA; Ronan da Silva Parreira; VITÓRIA, Alice da Silva; ROQUE, Ariel Teixeira. Candomblé no Brasil: resistência negra na diáspora africana. Jundiaí: Paco Editorial, 2020.

GONZALEZ, Lélia. A categoria político-cultural de amefricanidade. Tempo Brasileiro, Rio de Janeiro, n. 92/93, p. 69-82, jan./jun. 1988.

GOULART, Fransergio; CALVET, Rodrigo. Para que e para quem servem as pesquisas acadêmicas sobre as favelas?: uma nova epistemologia é possível! Canal IBase, Rio de Janeiro, 21 mar. 2017. Disponível em: http://www.canalibase.org.br/para-que-e-para-quemservem-pesquisas-academicas-sobre-favelas-uma-nova-epistemologia-e-possivel/. Acesso em: 23 mar. 2020.

HARRIS, Cheryl. Whiteness as a property. Harvard Law Review, v. 106, n. 8, p. 1707-1791, jun. 1993.

JESUS chorou. Intérprete: Racionais MC's. Compositor: M. Brown. In: Nada como um dia após outro dia. São Paulo: Casa Nostra/Zambia, 2002. 2 CDs, Faixa 4 (7min. 52 seg.), CD 1.

JORGE maravilha. Intérprete: Chico Buarque. Compositor: C. Buarque. In: BANQUETE dos mendigos. Intérprete: Jards Macalé. Rio de Janeiro: RCA, 1973. 2 discos vinil, disco 2, faixa 22 (1min.ogseg.).

MIRANDA, Marina; PORTILHO, Kaká. Além do universalismo feminista: a fenomenologia da existência da mulher afrodescendente no Brasil. In: CONGRESSO BRASILEIRO DE PESQUISADORES NEGROS, 10., 2018, Uberlândia. Anais [...]. Uberlândia: Universidade Federal de Uberlândia, 2018. Tema: (Re) Existência Intelectual Negra Ancestral. Disponível em: https://www.copene2018.eventos.dype.com.br/resources/anais/8/

1538341718_ARQUIV O_ModeloTrabalhoCompletoXCOPENE-26-06.pdf. Acesso em: 20 mar. 2020.

NASCIMENTO, Abdias do. 0 genocídio do negro brasileiro: processo de um racismo mascarado. 3. ed. São Paulo: Perspectivas, 2016. 232p.

NEGRO drama. Intérprete: Racionais MC's. Compositores: M. Brown; E. Rock. In: Nada como um dia após outro dia. São Paulo: Casa Nostra/Zambia, 2002. 2 CDs, faixa 5 (6min.53seg.), CD 1.

OLIVEIRA, Acauam Silvério de. O evangelho marginal dos Racionais MC's. In: RACIONAIS MC'S. Sobrevivendo no inferno. São Paulo: Companhia das Letras, 2018. p. 19-37. 
OLIVEIRA, Elaine Correia. Da periferia para o mundo: as vozes poéticas na letra Diário de um Detento. InterteXto, Uberaba, v. 11, n. 2, p. 116-131, 2018.

OLIVEIRA, Leandro Silva de; SEGRETO, Marcelo; CABRAL, Nara Lya Simões Caetano. Vozes periféricas: expansão, imersão e diálogo na obra dos Racionais MC's. Revista do Instituto de Estudos Brasileiros, n. 56, p. 101-126, 18 dez. 2013.

RAMIL, Tatiana. Mourão diz que família sem pai ou avô é 'fábrica de elementos desajustados'; candidatas reagem. Extra, Rio de Janeiro, 17 set. 2018. Disponível em: https://extra.globo.com/noticias/brasil/mourao-diz-que-familia-sem-pai-ou-avo-fabrica-deelementos-desajustados-candidatas-reagem-23077044.html. Acesso em: 27 mar. 2020.

REDEMPTION song. Intérprete: Bob Marley \& The Wailers. Compositor: B. Marley. In: Uprising. Intérprete: Bob Marley \& The Wailers. Island Records/Tuff Gong, 1980. 1 disco vinil, lado B, faixa 5 (3min. 47seg.).

RIBEIRO, Alan Augusto Moraes; FAUSTINO, Deivison Mendes. Negro tema, negro vida, negro drama: estudos sobre masculinidades negras na diáspora. Revista TransVersos, n. 10, p. 163-182, ago. 2017.

SANTOS, Joel Rufino dos; BARBOSA, Wilson do Nascimento. Movimento negro e crise brasileira, Atrás do muro da noite; dinâmica das culturas afro-brasileiras. Brasília: Ministério da Cultura/Fundação Cultural Palmares, 1994.

SANTOS, Hélio. A busca de um caminho para o Brasil: a trilha do ciclo vicioso. 2. ed. São Paulo: Editora Senac São Paulo, 2003.

SANTOS, Hélio. Hélio Santos: 11/11/2002. Publicado pelo canal Roda Viva. [S.I.: s.n.], 5 ago. 2015. 1 vídeo (87 min). Disponível em: https://www.youtube.com/watch?v=1e6HHctgWPk. Acesso em: 29 mar. 2019.

SEMPREVIVA ORGANIZAÇÃO FEMINISTA. PROSTITUIÇÃO. Uma abordagem feminista. Redação de Nalu Faria, Sônia Coelho e Tica Moreno. São Paulo: SOF, 2013. 22p. Disponível em: http://sof2.tempsite.ws/wpcontent/uploads/2014/02/

Prostituicao_uma_abordagem_feminista.pdf. Acesso em: 24 mar. 2020.

SILVA, Tainan Maria Guimarães Silva e. O colorismo e suas bases históricas discriminatórias. Direito UNIFACS-Debate Virtual, n. 201, p. 1-19, 2017. Disponível em: https://revistas.unifacs.br/index.php/redu/article/view/4760/3121. Acesso em 27 mar. 2020.

SODRÉ, Muniz. Pensar Nagô. Petrópolis: Vozes, 2017. 
SOUZA, Jessé. Subcidadania brasileira: para entender o país além do jeitinho brasileiro. Rio de Janeiro: LeYa, 2018. 288 p.

SOUZA, Neusa Santos. Tornar-se negro: ou as vicissitudes da identidade do negro brasileiro em ascensão social. 2. ed. Rio de Janeiro: Graal, 1990.

TOLEDO, Juliana Aparecida Cantarino; CASSAB, Clarice. O lazer, a periferia e os jovens: relações para discutir o crescimento pentecostal. Terra Livre, São Paulo, v. 1, n. 52, p. 608640, 2019. Disponível em:

https://www.agb.org.br/publicacoes/index.php/terralivre/article/view/1669. Acesso em: 30 ago. 2020.

VELECI, Nailah Neves. Cadê Oxum no espelho constitucional?: os obstáculos sóciopolítico-culturais para o combate às violações dos direitos dos povos e comunidades tradicionais de terreiro. 2017.145 f. Dissertação (Mestrado em Direitos Humanos e Cidadania) - Universidade de Brasília, Brasília, 2017.

XIBOM bombom. Intérprete: As Meninas. Compositores: R. Gaspar; W. Rangel. In: AS meninas. Xibom Bombom. Universal Music, 1999. 1 CD, faixa 1 (3min. 47seg.). 